\title{
A modified and simplified radiofrequency ablation in patients with mitral valve disease
}

Roland Fasol, MD, ${ }^{a}$ Johann Meinhart, PhD, and Thomas Binder, MD, ${ }^{\mathrm{b}}$ Vienna, Austria

See related editorial on page 1 . o eliminate atrial fibrillation (AF) in patients with mitral valve disease, the Cox maze procedure has been concomitantly performed. However, because it is an extensive and complex "cut and sew" technique, the procedure is complex to perform. As a consequence, easier to apply ablation methods were introduced that restore sinus rhythm (SR) and atrial contraction (AC) in more than $70 \%$ of treated patients. ${ }^{1}$ This has resulted in controversial discussions concerning the best possible ablation line patterns.

We have now modified, simplified, and reduced the currently applied complex saline-irrigated, cooled-tip radiofrequency ablation (SICTRA) ${ }^{1}$ procedure to a simple, effective, quick, and "easyto-apply" procedure in 10 consecutive patients $(50 \%$ were male, mean age $66.3 \pm 9.3$ years) with excellent results at a 1-year follow-up.

\section{Patients and Methods}

In 2002, 10 consecutive patients with mitral valve disease and chronic AF (preexisting $>6$ months) had their mitral valve repaired. Valvular disease was degenerative in 8 patients and ischemic in 2 patients.

Surgery. The details of mitral repair are listed in Table 1. The applied SICTRA set-up technique (Medtronic, Inc, Minneapolis, Minn) was previously published. ${ }^{1}$ Our modified and simplified "triangle-like" lesion pattern, isolating the right and left pulmonary veins as well as the suture-closed orifice of the left atrial appendage (not resected) and meeting at the midportion of the posterior mitral annulus, is described in detail in Figure 1.

\footnotetext{
From the Department of Cardiovascular Surgery, ${ }^{\text {a }}$ Hospital Lainz, and Department of Cardiology, ${ }^{\mathrm{b}}$ AKH, University of Vienna, Vienna, Austria. Received for publication March 7, 2004; accepted for publication April 6, 2004.

Address for reprints: Roland Fasol, MD, IMC-International Innovative Medical Care Center, Krustettnerstrasse, A-3506 Krems/Hollenburg, Austria (E-mail: rfasol@imc-hospital.com).

J Thorac Cardiovasc Surg 2005;129:215-7

$0022-5223 / \$ 30.00$

Copyright $\odot 2005$ by The American Association for Thoracic Surgery doi:10.1016/j.jtcvs.2004.04.022
}
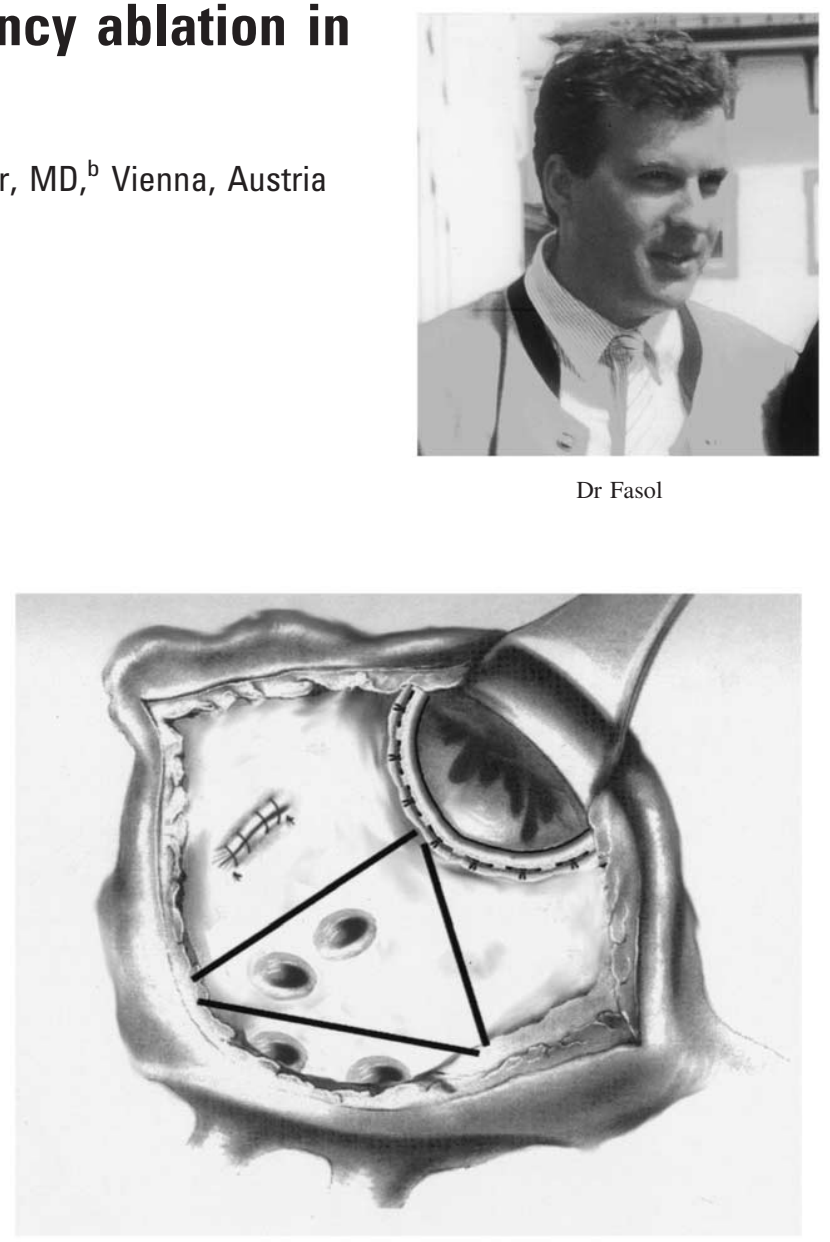

Figure 1. Intraoperative view of the left atrium showing suture closure of the left atrial appendage and simple "triangle-like" ablation lines, isolating the right and left pulmonary veins (as well as the suture-closed orifice of the left atrial appendage) and meeting at the midportion of the posterior mitral annulus.

Postoperative care. There was no specific protocol for this group of patients concerning medication or pacing, which differed from the usual hospital routine.

Follow-up. Patient data were obtained perioperatively, at the time of discharge from the hospital, 1 month postoperatively after discharge from the rehabilitation clinic, and at the time of the follow-up in September of 2003 (16.4 \pm 3.2 months, range 11-20 months). A medical history, clinical examination, and electrocardiogram were obtained at each visit. A transthoracic echocardiogram, including pulsed-wave Doppler of transmitral flow, was obtained at the time of follow-up.

\section{Results}

There were no early or late deaths. All patients were in SR when they were weaned from bypass. Four patients required perioperative pacemaker stimulation, because the heart rate was below 65 


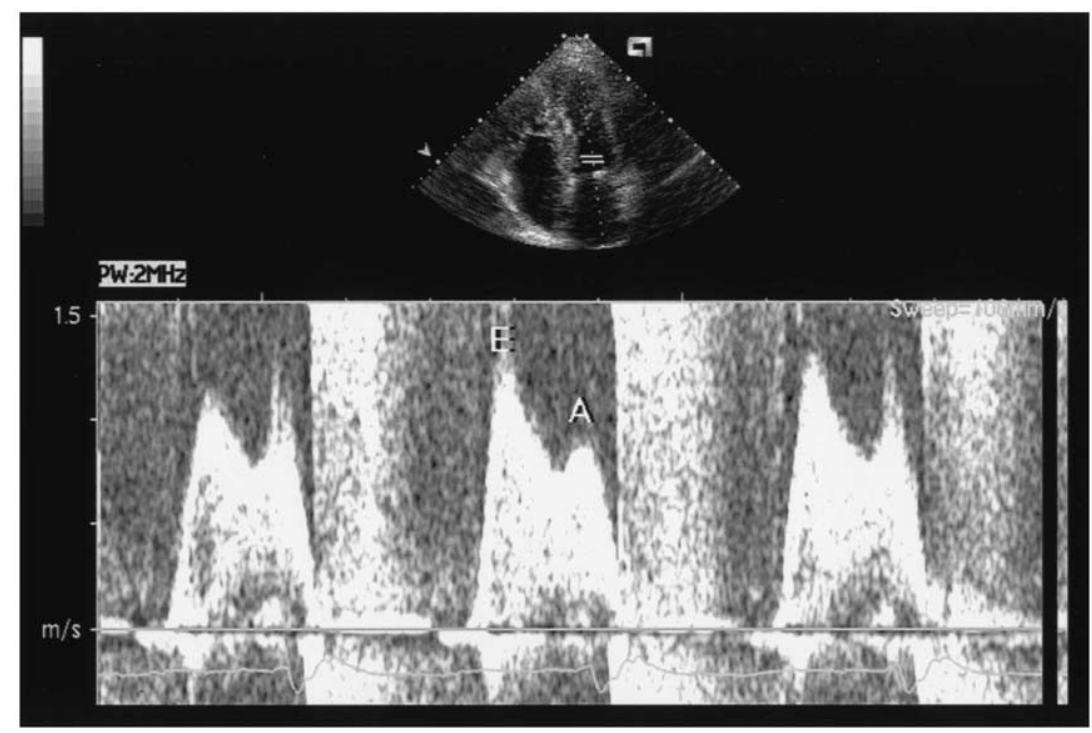

Figure 2. Pulsed wave Doppler spectrum across the mitral valve in a patient after the modified maze procedure. The presence of a distinct A-wave documents hemodynamic relevant atrial contraction. $E$, Early diastolic filling; $A$, atrial contraction.

beats/min, and 3 patients required postoperative cardioversion. Follow-up was $100 \%$ complete. The results of echocardiographic evaluation showed normal function of the repaired mitral valve in all patients. Rhythm was evaluated by electrocardiogram and Holter monitoring and detection of an A wave (AC) by Doppler echocardiography.

During follow-up, 6 patients received antiarrhythmic medications by their general practitioners (2 patients received type II antiarrhythmics [amiodarone] and 4 patients received beta blockers [metoprolol]). At the time of follow-up, 90\% were in New York Heart Association functional class I or II. All patients described their quality of life as significantly improved compared with their preoperative quality of life. Only 3 patients were kept on antiarrhythmic medications ( 2 patients received beta blockers, and 1 patient received type II antiarrhythmics). There were no late cardiac-related reoperations or other complications. At the time of follow-up, all but 2 patients were in continuous and stable SR. These 2 patients received warfarin sodium (Coumadin). One patient required a pacemaker because of intermittent SR bradycardia, and 1 patient had occasional periods of intermittent AF. Nevertheless, a hemodynamic relevant $\mathrm{AC}$ was well documented in all patients (Figure 2).

\section{Discussion}

The motivation to perform this pilot study was to assess the possible effectiveness of a simple and "easy-to-apply" technique to interrupt macro-reentry circles to eliminate AF in patients with mitral valve disease, because the authors judged the currently available ablation techniques as too time-consuming and often too difficult or "uncomfortable" to perform. Therefore, our mean crossclamp time of 42 minutes was comparable with that reported in other studies (103 minutes ${ }^{1}$ and 99 minutes $^{2}$ ). Furthermore, because reports of possible complications such as atrial-esopha- geal fistulas, pulmonary vein orifice injury, and massive air embolism started to surface, we explored a less invasive, simpler, and safer technique to avoid such complications. ${ }^{3,4}$ We demonstrated that our simple "triangle-like" ablation lines (Figure 1) met all the essential requirements to eliminate AF; are simple, easy, and quick to perform; are obviously not hampered by some of the reported possible complications; and effectively eliminated AF in every patient up to the present.

The idea behind our concept of a simplified SICTRA technique was also to reduce the amount of atrial tissue being "destroyed" (ablated) and subsequently reducing the time required to perform this technique. We are convinced that the postoperative function of the left atrium and its subsequent hemodynamic relevant AC may correlate to the amount of left atrial tissue being damaged or ablated. Our results therefore also showed a hemodynamic relevant AC in every patient, although the result in one of our patients is limited by occasional incidences of intermittent AF. In contrast, AC, or hemodynamic relevant atrial activity, was shown to be present in $66 \%$ to $91 \%{ }^{1,5}$ of all treated patients and was not even assessed in other studies. ${ }^{2}$ Furthermore, we did not resect the left atrial appendage; the orifice was suture closed to avoid possible bleeding complications. We also did not use a right atrial ablation, because the expected incidence of AF recurrence caused by foci from the right atrium is approximately only $10 \%$ to $14 \% .^{5}$

\section{Conclusion}

It may be assumed that our modified and simplified ablation technique proved to be effective and showed promising results. However, larger patient numbers and a longer follow-up will be required to prove the long-term effectiveness of this modified technique. 
TABLE 1. Surgical procedures

\begin{tabular}{lcll}
\hline Associated procedures & No. & Mitral repair procedures & No. \\
\hline CABG & 3 & Resection of posterior leaflet & 4 \\
TVR & 1 & Resection of anterior leaflet & 1 \\
& & PTFE chordae implantation* & 3 \\
& & Papillary muscle shortening & 2 \\
\hline \hline
\end{tabular}

Preoperative and postoperative echochardiographic parameters

\begin{tabular}{lccc}
\hline Characteristics & Preoperative & Postoperative & 1-yr follow-up \\
\hline LA $(\mathrm{mm})$ & $55.4 \pm 6.8$ & $49.2 \pm 5.4$ & $41.4 \pm 6.2 \dagger$ \\
LVED $(\mathrm{mm})$ & $65.2 \pm 5.1$ & $60.8 \pm 5.5$ & $51.2 \pm 7.3 \dagger$ \\
LVES $(\mathrm{mm})$ & $43.5 \pm 3.9$ & $41.2 \pm 6.1$ & $36.1 \pm 8.4$
\end{tabular}

$C A B G$, Coronary artery bypass graft; TVR, tricuspid valve repair; $L A$, left atrial; $L V E D$, left ventricular end-diastolic; $L V E S$, left ventricular end-systolic; PTFE, polytetrafluoroethylene.

*Chordal replacement with a 4.0 PTFE suture.

$\dagger$ Values differ significantly from preoperative values $(P<.1)(t$ test for paired samples and Wilcoxon matched-pairs signed-ranks test).

\section{References}

1. Khargi K, Deneke T, Haardt H, Lemke B, Grewe P, Müller KM, et al. Saline-irrigated, cooled-tip radiofrequency ablation is an effective technique to perform the maze procedure. Ann Thorac Surg. 2001;72: S1090-5.

2. Schuetz A, Schulze C, Sarvanakis K, Mair H, Plazer H, Kilger E, et al. Surgical treatment of permanent atrial fibrillation using microwave energy ablation: a prospective and randomized clinical trial. Eur J Cardiothorac Surg. 2003;24:475-80.

3. Gillinov M, Peterson G, Rice TH. Esophageal injury during radiofre- quency ablation for atrial fibrillation. $J$ Thorac Cardiovasc Surg. 2001;122:1239-40.

4. Mohr F, Fabricius A, Falk V, Autschbach R, Doll N, von Oppel U, et al. Curative treatment of atrial fibrillation with intraoperative radiofrequency ablation: short term and midterm results. $J$ Thorac Cardiovasc Surg. 2002;123:919-27.

5. Sie H, Beukema W, Misier A, Elvan A, Ennema J, Wellens H. The radiofrequency modified maze procedure. A less invasive surgical approach to atrial fibrillation during open-heart surgery. Eur J Cardiothorac Surg. 2001;19:443-7.

\section{Inhaled nitric oxide does not improve systemic oxygenation after bidirectional superior cavopulmonary anastomosis}

Ian Adatia, MBChB, ${ }^{a, b}$ Andrew M. Atz, MD, ${ }^{a}$ and David L. Wessel, MD, ${ }^{a}$ Boston, Mass, and Toronto, Ontario, Canada

$\mathrm{I}$ nhaled nitric oxide (NO) is a selective pulmonary vasodilator that decreases intrapulmonary shunt fraction. ${ }^{1}$ We sought to determine whether inhaled $\mathrm{NO}$ would ameliorate hypoxemia after bidirectional superior cavopulmonary anastomosis (BCPA).

\footnotetext{
From the Department of Cardiology, Children's Hospital, and Departmen of Pediatrics, Harvard Medical School, ${ }^{\text {a }}$ Boston, Mass, and Department of Critical Care Medicine and Division of Cardiology, Hospital for Sick Children Toronto, ${ }^{\mathrm{b}}$ Toronto, Ontario, Canada.

Received for publication April 5, 2004; accepted for publication April 13, 2004.

Address for reprints: Ian Adatia, MBChB, University of California at San Francisco Children's Hospital, 505 Parnassus Ave, Room M-655, San Francisco, CA 94143-0106 (E-mail: iadatia@ @edcard.ucsf.edu).

J Thorac Cardiovasc Surg 2005;129:217-9

$0022-5223 / \$ 30.00$

Copyright $\odot 2005$ by The American Association for Thoracic Surgery doi:10.1016/j.jtcvs.2004.04.024
}

\section{Methods}

The research and ethics review board approved the study, and the parents of all children gave informed and written consent. We included patients with systemic oxygen saturations of $75 \%$ or less after BCPA without venous decompressing collaterals or pulmonary disease. Patients were mechanically ventilated and studied on the first postoperative day in the intensive care unit. From a stable baseline, patients received a 15-minute trial of inhaled NO (80 $\mathrm{ppm}){ }^{2}$ During the trial of inhaled NO, ventilator parameters and $\mathrm{FIO}_{2}$ were unchanged. In 5 patients, cyclic guanosine monophosphate (cGMP) levels were measured. ${ }^{2}$ One patient first received inhaled NO in the cardiac catheterization laboratory because of persistent hypoxemia after coil embolization of decompressing venous collaterals. This same patient was readmitted 7 months after BCPA with refractory hypoxemia as the result of respiratory syncytial viral pneumonitis and was treated with $10 \mathrm{ppm}$ NO.

\section{Statistical Analysis}

A paired Student $t$ test with a Bonferroni correction for 3 comparisons was used. The difference between cGMP levels was compared by the nonparametric Wilcoxon signed-rank test. 